\title{
FREE ENTRY AND SOCIAL EFFICIENCY UNDER UNKNOWN DEMAND PARAMETERS
}

\author{
Batlome Janjgava
}

Charles University

Center for Economic Research and Graduate Education

Academy of Sciences of the Czech Republic

Ec onomic Institute
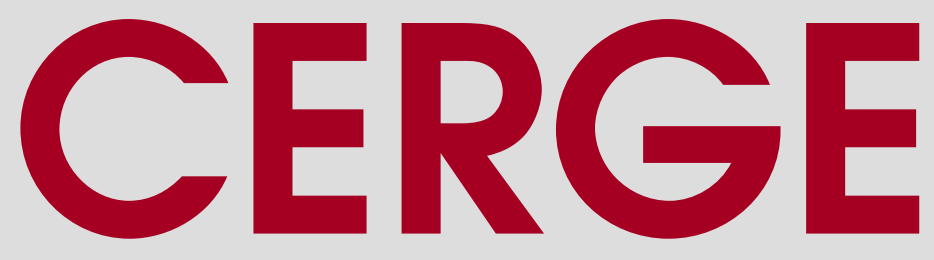


\title{
Working Paper Series 495 (ISSN 1211-3298)
}

\section{Free Entry and Social Efficiency under Unknown Demand Parameters}

\author{
Batlome Janjgava
}

CERGE-EI

Prague, October 2013 
ISBN 978-80-7343-299-7 (Univerzita Karlova. Centrum pro ekonomický výzkum a doktorské studium)

ISBN 978-80-7344-291-0 (Akademie věd České republiky. Národohospodářský ústav) 


\title{
Free Entry and Social Efficiency under Unknown Demand Parameters *
}

\author{
Batlome Janjgava $^{\dagger}$
}

\begin{abstract}
In the paper, I examine free entry in homogeneous product markets and its social efficiency. Previous research on free entry in homogeneous product markets has shown that under Cournot oligopoly with fixed setup costs the free entry equilibrium always delivers excessive entry. In contrast, I demonstrate in this paper that free entry along with excessive entry might also lead to a socially insufficient number of firms when a demand parameter uncertainty is considered. My findings support the validity of the traditional wisdom in industrial organization that free entry is desirable for social efficiency and call for revision of restrictive entry regulation practices which been based on previous research findings.
\end{abstract}

Keywords: Free Entry, Welfare, Collusion, Beliefs, Learning, Self-Confirming Equilibrium, Escape Dynamics

JEL Classification: D60, D83, D43, L13, L40, L51

${ }^{\star}$ I am grateful to Sergey Slobodyan for helpful discussions, comments and continuous support. I would like also to thank Krešimir Zigic and Fabio Michelucci for valuable comments and suggestions. All remaining errors are the responsibility of the author. The financial support of the Czech Science Foundation project No. P402/12/G097 DYME Dynamic Models in Economics is acknowledged. E-mail: batlome.janjgava@cerge-ei.cz

${ }^{\dagger}$ CERGE-EI, a joint workplace of Charles University in Prague and the Economics Institute of the Academy of Sciences of the Czech Republic, Politickych veznu 7, 11121 Prague, Czech Republic 


\begin{abstract}
Abstrakt
V tomto článku se zabývám volným vstupem na trhy s homogenními produkty a jejich společenskou efektivitou. Předchozí výzkum volného vstupu na trhy s homogenními produkty ukázal, že za předpokladu Cournotova modelu oligopolu s fixními náklady, volný vstup vede $\mathrm{k}$ nadměrnému vstupu firem. $\mathrm{V}$ kontrastu $\mathrm{k}$ tomuto demonstruji $\mathrm{v}$ tomto článku, že volný vstup spolu s nadměrny̌m vstupem firem může také vést $\mathrm{k}$ společensky nedostatečnému počtu firem, pokud budeme uvažovat nejistotu ohledně parametrů poptávky. Moje závěry podporují tradiční pohled v organizaci trhů a odvětví, že volný vstup je žádoucí pro společenskou efektivitu a vyzývá k revizi restriktivních regulačních praktik vůči volnému vstupu, které byly založeny na základě předchozího výzkumu.
\end{abstract}




\section{Introduction}

In general, free entry is assumed to be desirable for a society from a social welfare point of view and has been traditional wisdom among economic professions. However, many economists have challenged this view and showed that in homogeneous product markets with imperfect competition, when firms pay a fixed set-up cost upon entry, the free entry equilibrium number of firms exceeds the socially optimum number of firms, known as the excess entry theorem, see Weizsaker (1980), Perry (1984), Mankiw and Whinston (1986), Suzumura and Kiyono (1987), Berry and Waldfogel (1999), Ohkawa, Okamura, Nakanishi, and Kiyono (2005). ${ }^{1}$ In this paper, I study the social efficiency of free entry and show that the excess entry theorem might not hold in the homogenous product markets when the demand parameter uncertainty is considered.

The most prominent work, which provided the first excess entry theorem results under general settings and provoked intensive research in this area, is Mankiw and Whinston (1986). They find that free entry is not socially desirable due to a so called "business stealing" effect which is present when "... the equilibrium output per firm declines as the number of firms grow". Due to new entry, incumbent firms are forced to reduce output and entry is more desirable to new entrants than it is to society, implying excessive entry under free entry.

The excess entry theorem advocates restrictive entry polices; but under restricted entry a fixed number of firms operate in the market, and firms' recognition of their mutual interdependence might propagate a collusive pricing behavior. The latter idea goes back to Chamberlin (1929) and is not captured by the excess entry theorem. The higher number of firms might hinder the propagation of such collusive pricing behavior and entry acquires an additional effect, i.e. the "competition" effect. This has an opposite impact on social welfare than the "business stealing" effect and makes entry more desirable for society. Hence, if the "competition" effect is present, the results of the excess entry theorem might not hold, or would depend on the net gain from entry and not only on the

\footnotetext{
${ }^{1}$ For a recent discussion of the excess entry theorem one can refer to Suzumura (2012).
} 
"business stealing" effect.

The purpose of my paper is to reexamine the social efficiency of free entry under the settings of Mankiw and Whinston (1986), but explicitly modeling for the mutual interdependence of firms and the "competition" effect missing there. The building blocks of the model in the paper are the same as in Mankiw and Whinston (1986) but in addition I assume a market with a linear inverse demand curve where demand parameters, a slope and an intercept, are unknown to firms. Firms observe only price and their own output and do not observe their rivals' output.

To make production decisions, firms form beliefs about unknown parameters and unobserved rivals' output. After the production decision is made, a new market price is realized and firms update their beliefs using Bayes' rule. Additionally, beliefs are required to be consistent with the observations. This leads to the notion of the self-confirming equilibrium (SCE) as the solution concept (see Fudenberg and Levine (1993), Sargent (1999), Sargent (2008)).

The SCE is less restrictive than the Nash equilibrium and does not require firms to have correct beliefs off the equilibrium path. Firms are aware of this and are interested to generate more information about the off-equilibrium path by an "experimentation" to see if they have appropriate beliefs. ${ }^{2}$ The "experimentation" is modeled as random perturbations over a firm's best response to its current beliefs maximizing the instantaneous expected profit. The "experimentation" is costly in terms of forgone instantaneous expected profit and firms are assumed to keep the variation of random perturbations close to zero.

Dekel, Fudenberg, and Levine (2004), studying games without common priors about Nature's move and unobserved opponents' play, show that the set of SCE might include non-Nash outcomes. As firms, in my model, observe neither Nature's nor opponents' moves, (in line with Dekel, Fudenberg, and Levine (2004)) one might expect the SCE to include non-Nash outcomes. Janjgava and Slobodyan (2011), in similar settings to

\footnotetext{
${ }^{2}$ For detailed considerations about "experimentation" see Fudenberg and Levine (2009).
} 
those in my model but for the duopoly case, show that firms might engage in cooperative behavior if their beliefs become interdependent enough to coordinate their actions. I extend the model developed in Janjgava and Slobodyan (2011) for the oligopoly case, and find that their findings remain valid in the case of oligopoly as well. In addition, I identify the conditions when the interdependence, which leads to cooperative behaviors, might arise.

In my model, as firms might be engaged in cooperative behavior, the "competition" effect of entry becomes operative. As far as the "competition" effect enhances social welfare, in contrast to the "business stealing" effect, entry has a higher social value under demand uncertainty than in the case of the perfect information of Mankiw and Whinston (1986). I find that for lower fixed-setup costs, the results of the excess entry theorem is altered, and the optimal number of firms under demand uncertainty coincides with the free entry number of firms. Thus, the results of the paper highlight the importance of the demand parameter uncertainty for the social desirability of free entry and finds support for the traditional wisdom.

The rest of the paper is organized as follows. Section 2 presents the model, develops the firms' decision problem, and formation and updating of beliefs. Section 3 defines the self-confirming equilibrium that coincides with the Cournot-Nash equilibrium of the model and a dominant escape path from it. In Section 4, I study the conditions under which implicit coordination towards collusion is impossible and define the collusion frontier. Section 5 introduces free entry and considers the social planner's problem under free entry when implicit coordination on collusive outcomes might arise endogenously. Finally, Section 6 concludes.

\section{The Model Setup}

Consider an oligopolistic industry comprised of $N$ firms producing a single, homogeneous good where explicit collusion is forbidden by the antitrust law. It is assumed that 
firms possess a homogeneous production technology with a constant marginal cost $c$ and a fixed setup cost $K$. The industry faces a linear inverse demand schedule:

$$
y_{n}=a-b Q_{n}
$$

where $a$ and $b$ are unknown positive constants, and $Q_{n}=Q_{n}^{-i}+q_{n}^{i}$ is industry supply; $q_{n}^{i}$ stands for a firm $i^{\prime}$ s individual output and $Q_{n}^{-i}$ is rivals' output and not observed by the firm $i$.

- A firm's decision problem. Given the linear inverse demand function firm $i$ constructs a linear subjective model of demand

$$
y_{n}^{i}=x_{i n}^{\top} \theta_{n}^{i}+u_{n}^{i}
$$

where $x_{i n}=\left(1, q_{n}^{i}\right)^{\top} ; \theta_{n}^{i}=\left(a-b Q_{n}^{-i},-b\right)^{\top} \in \Theta$ is a vector of unknown parameters; the error term $u_{n}^{i} \sim N\left(0, \sigma^{2}\right)$ captures the possibility of mistakes in constructing the subjective model.

Define history in period $n$ as $h_{n}^{i}=\left\{y_{s}, q_{s}^{i}\right\}_{s=1}^{n-1}$. At the beginning of each period $n$, firm $i$ updates its prior beliefs $\mu_{n-1}^{i}\left(\theta_{n}^{i} \mid h_{n-1}^{i}\right)=P\left(\theta_{n}^{i} \mid h_{n-1}^{i}\right)$ over $\Theta$, the set of unknown parameters, given the realized price $y_{n-1}$ using the Bayes' rule

$$
\mu_{n}^{i}\left(\theta_{n}^{i} \mid h_{n}^{i}\right) \propto P\left(h_{n}^{i} \mid \theta_{n}^{i}, h_{n-1}^{i}\right) \mu_{n-1}^{i}\left(\theta_{n}^{i} \mid h_{n-1}^{i}\right)
$$

Given the current beliefs $\mu_{n}^{i}\left(\theta_{n}^{i} \mid h_{n}^{i}\right)$, firm $i$ solves the profit maximization problem

$$
\pi_{n}^{i}=\max _{q_{n}^{i}} \int_{\Theta}\left(\left(x_{i n}^{\top} \theta_{n}^{i}+u_{n}^{i}-c\right) q_{n}^{i}-K\right) d \mu_{n}^{i}\left(\theta_{n}^{i} \mid h_{n}^{i}\right),
$$

which yields the following decision rule

$$
\hat{q}_{n}^{i}=\max \left\{\frac{\hat{\theta}_{0 n}^{i}-c}{-2 \hat{\theta}_{1 n}^{i}}, 0\right\},
$$


where $\hat{\theta}_{n}^{i}=\int_{\Theta} \theta_{n}^{i} d \mu_{n}^{i}\left(\theta_{n}^{i} \mid h_{n}^{i}\right)$.

Firm $i^{\prime} s$ belief $\mu_{n}^{i}$ is required to be consistent with observations and the solution concept becomes the self-confirming equilibrium (SCE). The SCE is less restrictive than the Nash equilibrium and does not require firms to have correct beliefs off the equilibrium path. Firms are aware of this and are interested in generating more information about the off-equilibrium path by an "experimentation" to see if they have appropriate beliefs. ${ }^{3}$

The "experimentation" is modeled as a random perturbation over firm i's best response to its current beliefs and the final production decision is given as

$$
q_{n}^{i}=\hat{q}_{n}^{i}+\omega_{n}^{i}
$$

where $\omega_{n}^{i}$ is assumed to be an ex post privately observable Gaussian white noise.

The "experimentation" is costly in terms of the forgone expected profit and $i$ is interested in keeping the variation of random perturbation $\omega_{n}^{i}$ close to zero.

- A firm's estimation model. Firms anticipate that, due to learning, the actual environment is not stationary and thus, the opponents' strategies should not be stationary either. Hence, it is assumed that firms consider unknown parameters $\theta_{n}^{i}$ as time-varying and adopt a time-varying parameter (TVP) estimation model $^{4}$

$$
\begin{aligned}
& y_{n}^{i}=x_{i n}^{\top} \theta_{n}^{i}+u_{n}^{i}, \\
& \theta_{n}^{i}=\theta_{n-1}^{i}+\eta_{n}^{i},
\end{aligned}
$$

where $\eta_{n}^{i} \sim N\left(0, V_{i}\right)$.

Given the estimation model (6), firm $i$ updates their beliefs $\mu_{n}^{i}\left(\theta_{n}^{i} \mid h_{n}^{i}\right)$, represented by a normal distribution

$$
\theta_{n}^{i} \mid h_{n}^{i} \sim N\left(\hat{\theta}_{n}^{i}, \sigma^{2} \hat{P}_{n}^{i}\right)
$$

\footnotetext{
${ }^{3}$ For detailed considerations about the "experimentation" see Fudenberg and Levine (2009).

${ }^{4} \mathrm{TVP}$ is commonly used in learning literature in the industrial organization as well as in macroeconomics: see Slade (1989), Balvers and Cosimano (1990), Balvers and Cosimano (1993), Sargent (1999), Cho, Williams, and Sargent (2002).
} 


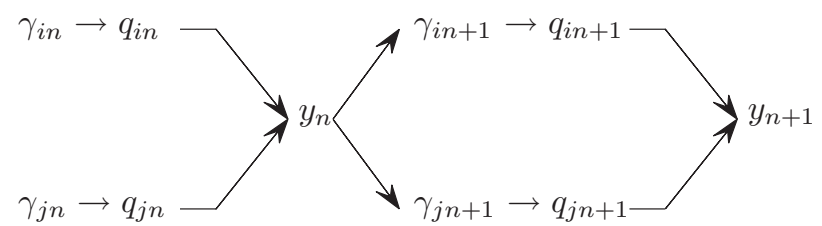

Figure 1. Timing of the model

recursively using the Kalman filter equations

$$
\begin{aligned}
& \hat{\theta}_{n+1}^{i}=\hat{\theta}_{n}^{i}+\frac{\hat{P}_{n}^{i}}{1+x_{i n}^{\top} \hat{P}_{n}^{i} x_{i n}} x_{i n}\left(y_{n}^{i}-x_{i n}^{\top} \hat{\theta}_{n}^{i}\right), \\
& \hat{P}_{n+1}^{i}=\hat{P}_{n}^{i}-\frac{\hat{P}_{n}^{i} x_{i n} x_{i n}^{\top} \hat{P}_{n}^{i}}{1+x_{i n}^{\top} \hat{P}_{n}^{i} x_{i n}}+\frac{1}{\sigma^{2}} V_{i},
\end{aligned}
$$

where $\hat{P}_{n}^{i}=\sigma^{-2} \operatorname{cov}\left[\theta_{n}^{i}-\hat{\theta}_{n}^{i}\right]$. The Kalamn filter, given the normality assumptions, is equivalent to the Bayesian updating rule (3). ${ }^{5}$

- Timing. The timing of the decision process is illustrated in Figure 1. At the beginning of each period $n$, given the current beliefs $\mu_{n}^{i}$ over the set of unknown parameters $\Theta$, firm $i$ makes production decisions $q_{n}^{i}$ given by (5). After production decisions are made and output is supplied to the market, the market price $y_{n}$ is realized according to its true data generating process

$$
y_{n}=a-b \sum_{i=1}^{N} q_{n}^{i} .
$$

At the beginning of the next period $n+1$ firm $i$ observes the realized price and updates its prior beliefs $\mu_{n}^{i}$ over $\Theta$ using (7) by $\mu_{n+1}^{i}$ and the cycle of production and belief updating process starts over.

\section{Self-confirming Equilibrium}

Equilibrium in the model is defined by the self-confirming equilibrium (SCE) developed by Fudenberg and Levine (1993) and adopted for adaptive learning literature in macroeconomics by Sargent (1999).

\footnotetext{
${ }^{5}$ See for instance Slade (1989), Balvers and Cosimano (1990) for the Kalamn filter applications in IO and for derivations one can consult Harvey (1992), Ljungqvist and Sargent (2004).
} 
DEFINITION 1. SCE is a pair of belief and action $(\bar{\theta}, \bar{q})$ s.t. given the belief $\bar{\theta}$ the action $\bar{q}$ solves a firm's decision problem (4), $\bar{q}=\hat{q}_{n}^{i}(\bar{\theta})$ and given the action $\bar{q}$ the belief $\bar{\theta}$ is consistent with observations

$$
\mathrm{E}\left[x_{i n}\left(y_{n}-x_{i n}^{\top} \bar{\theta}\right)\right]=0 .
$$

Solving for beliefs in the above orthogonality condition we get

$$
\left[\begin{array}{l}
\theta_{0}^{i} \\
\theta_{1}^{i}
\end{array}\right]=\left[\begin{array}{l}
a-b \mathrm{E}\left[Q_{n}^{i}\right]+\rho b \mathrm{E}\left[q_{n}^{i}\right] \\
-b(1+\rho)
\end{array}\right],
$$

where $\rho=\operatorname{cov}\left[\sum_{j \neq i}^{N} q_{j n}, q_{n}^{i}\right] / \operatorname{var}\left[q_{n}^{i}\right]$ and also can be recognized as a conjectural variations parameter.

By definition in the SCE the conjectural variations parameter $\rho$ is zero as the SCE action $\bar{q}$ solves a firm's maximization problem (4) where rivals' quantity are taken as given. From the industrial organization literature we know that the conjectural variations parameter $\rho$ measures the degree of collusion; $\rho=0$ corresponds to the Nash equilibrium (NE) whereas $\rho=N-1$ corresponds to the collusive equilibrium (CE). Therefore, the SCE belief and action pair coincides with the NE.

Solving (9) for $\rho=0$ and $\rho=N-1$ provides with the following belief and action pairs

$$
\begin{aligned}
& (\bar{\theta}, \bar{q})=\left(\left[\frac{2 a+(N-1) c}{N+1},-b\right]^{\prime}, \frac{a-c}{b(N+1)}\right), \\
& (\tilde{\theta}, \tilde{q})=\left([a,-b N]^{\prime}, \frac{a-c}{2 b N}\right),
\end{aligned}
$$

respectively. We can verify that the action $\bar{q}$ at $\rho=0$ corresponds to the Nash equilibrium output whereas the action $\tilde{q}$ at $\rho=N-1$ corresponds to the collusive equilibrium output where firms maximize joint profits.

- Dominant escape path. Analytical tractability of the model requires the use of a system of ODEs associated with the discreet time belief updating system (7). Following Sargent and Williams (2005), the dynamics of $\left\{\theta_{n}, P_{n}\right\}$ generated by (7) converge weakly to the 


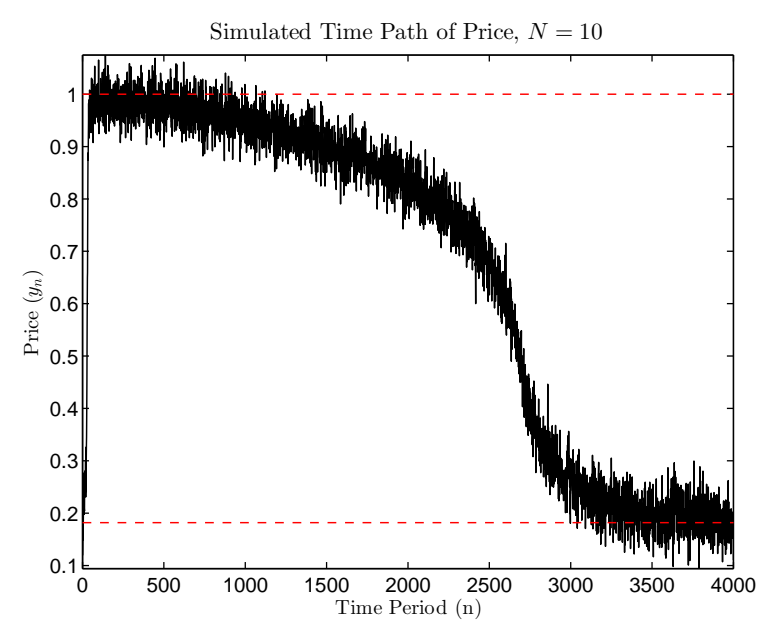

(a)

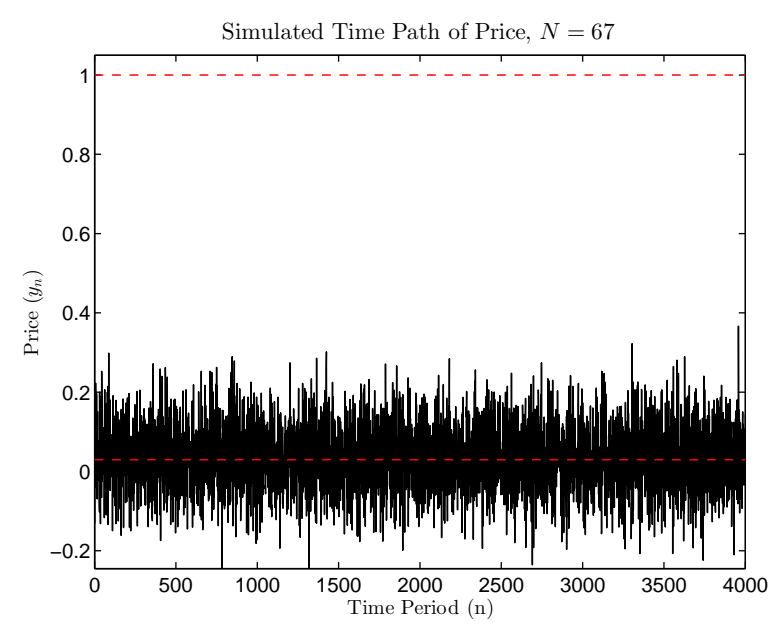

(b)

FIgURE 2. The simulated time path of price, $\left(a=2, b=0.1, \sigma_{2}=0.1, \epsilon=1 / 365\right)$ : for a lower number of firms we observe escapes towards the higher CE price (a) whereas for a higher number of firms we do not (b); the red dashed lines shows the SCE/NE and the CE prices.

solution of the following system of ODEs, called mean dynamics:

$$
\begin{aligned}
\dot{\theta}^{i} & =P^{i} \bar{g}\left(\theta^{i}, \ldots, \theta^{N}\right), \\
\dot{P}^{i} & =\sigma^{2} \bar{V}-P^{i} M\left(\theta^{i}\right) P^{i}, \\
i & =1, \ldots, N,
\end{aligned}
$$

where $\bar{g}\left(\theta^{i}, \ldots, \theta^{N}\right)=\mathrm{E}\left[x_{i n}\left(y_{n}-x_{i n}^{\top} \theta^{i}\right)\right], M\left(\theta^{i}\right)=\mathrm{E}\left[x_{i n} x_{i n}^{\top}\right]$, and $\bar{V}=\sigma^{2} M(\bar{\theta})^{-1}$.

We can show that the system of ODEs (12) has a unique E-stable steady-state which coincides with the SCE (see Appendix A for derivations). Despite the fact that the SCE is E-stable, simulating the belief updating system (7) we can observe recurrent escapes from the SCE towards the CE, see Figure 2a. At time 0, firms' beliefs constitute the SCE beliefs $\bar{\theta}$ but after some time, when they start to update beliefs, their beliefs escape from the SCE and firms start to coordinate their actions towards the collusive equilibrium price, which for the given parametrization is equal to 1 . This behavior depends on the number of firms. For a higher number of firms, beliefs, and consequently the market price, stay in the vicinity of the SCE and the collusive behavior is not observed, see Figure $2 \mathrm{~b}$.

As firms are homogeneous, imposing symmetry allows us to get rid of the subscript $i$ 
and concentrate on the mean dynamics of a single firm

$$
\begin{aligned}
& \dot{\theta}=P \bar{g}(\theta, N), \\
& \dot{P}=\sigma^{2} \bar{V}-P M(\theta) P,
\end{aligned}
$$

Following Kolyuzhnov, Bogomolova, and Slobodyan (2006), in the system of ODEs (13), if escapes from the SCE happen they occur along the direction of the dominant eigenvector of $\bar{P}$, as $\lambda_{1} / \lambda_{2} \gg 1$ where $\lambda_{1}$ and $\lambda_{2}$ are eigenvalues of $\bar{P} .6$

The dominant eigenvector can be approximated by

$$
\bar{v}=\left[\begin{array}{c}
\bar{q} \\
-1
\end{array}\right],
$$

which has the direction that coincides with the direction of a line connecting the SCE and the CE beliefs. Thus, the escape path from the SCE towards the CE is given by the following line:

$$
\Gamma=\{\theta \mid \theta=\bar{\theta}+\delta \bar{v}, \delta \in \mathbb{R}\}
$$

To derive an intuitive explanation of the dominant escape path $\Gamma$ from the SCE we can look more closely at the orthogonality condition (9). The orthogonality condition (9) evaluated at the SCE can be expressed as

$$
\begin{aligned}
\theta=\left[\begin{array}{l}
\theta_{0} \\
\theta_{1}
\end{array}\right] & =\left[\begin{array}{c}
\frac{2 a+(N-1) c}{N+1} \\
-b
\end{array}\right]+b \rho\left[\begin{array}{c}
\bar{q} \\
-1
\end{array}\right] \\
& =\bar{\theta}+b \rho \bar{v} .
\end{aligned}
$$

${ }^{6}$ We can perform the following decomposition

$$
\bar{P} \bar{g}(\theta, N)=H \Lambda H^{\prime} \bar{g}(\theta, N)=\lambda_{1} c_{1} v_{1}+\lambda_{2} c_{2} v_{2},
$$

where $\Lambda$ is a diagonal matrix formed from the eigenvalues of $\bar{P}$, and the columns of $H=\left[\begin{array}{ll}v_{1} & v_{2}\end{array}\right]$ are the corresponding eigenvectors of $\bar{P}$, and $c_{i}=H_{i}^{\prime} \bar{g}(\theta, N)$.

As $\lambda_{1} / \lambda_{2} \gg 1$ the second term in (14) becomes negligible and we obtain $\bar{P} \bar{g}(\theta, N) \approx \lambda_{1} c_{1} v_{1}$. Thus, the dynamics of the system (13) are concentrated along the direction of dominant eigenvector $v_{1}$ of $\bar{P}$. For a similar idea one can refer to principal component analysis widely used in the econometrics literature (see for example Stock and Watson (2002), Bai and Ng (2002), Bernanke and Boivin (2003)). 


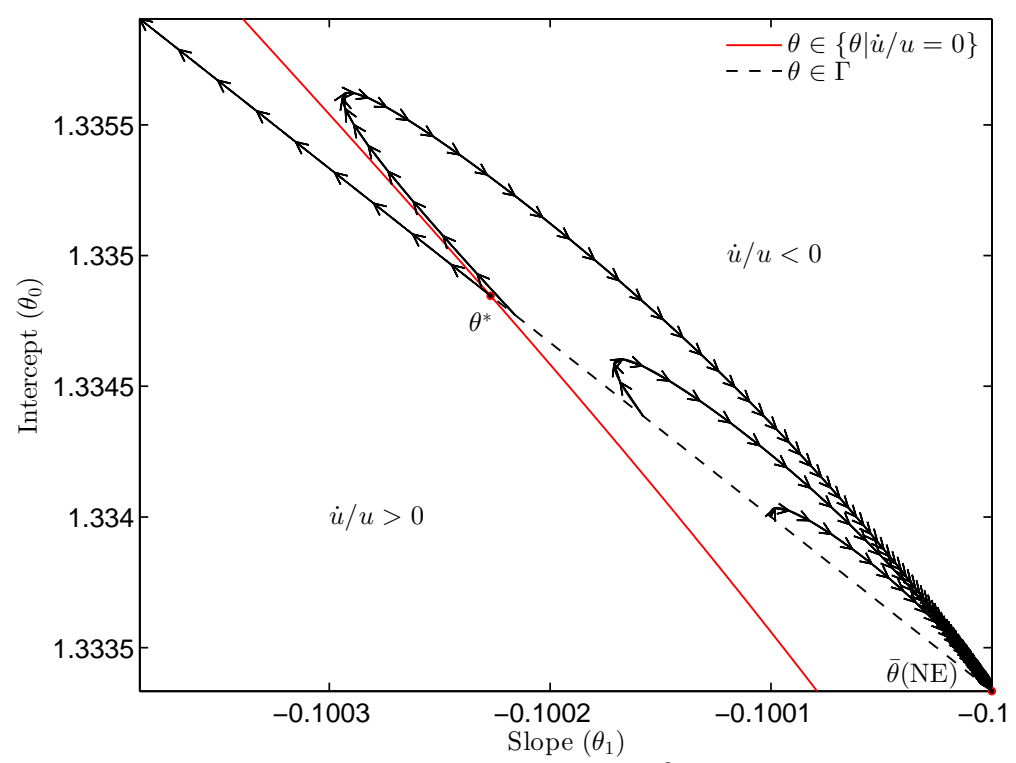

Figure 3. Phase diagram of beliefs, $a=2, b=0.1, \sigma_{2}^{2}=0.01, N=2$. Two types of mean belief trajectories are depicted: one with initial beliefs inside the attraction region of SCE along the dominant escape path and another for initial beliefs outside the attraction region of SCE along the dominant escape path. Mean belief trajectories are shown by arrows.

The expression (16) defines a belief evolution in the neighborhood of SCE. This implies that the firms' belief vector $\theta$ escapes the SCE whenever the firms' beliefs and consequently firms' actions become interdependent, $\rho$ the conjectural variations parameter becomes positive. Expression (16) represents the same relationship as in (15) and, together with (15) shows that the deviation from the SCE in its neighborhood happens along the direction of $\bar{v}$. As mentioned earlier, the direction of $\bar{v}$ coincides with the direction of a line connecting the SCE and the CE beliefs. Hence, if escape from the SCE happens it happens towards the CE.

The belief updating procedure (7) and its stochastic approximation (13) drives beliefs in a manner so as to minimize the mean forecast error $u=\mathrm{E}\left[u_{n}^{i}\right]$. Hence, to understand the properties of the belief updating system one should look at the mean dynamics of the forecast error, namely $\dot{u} / u{ }^{7}$ When $\dot{u} / u<0$, belief updating slows down as the mean forecast error $u$ moves towards zero, whereas when $\dot{u} / u>0$ belief updating speeds up as the mean forecast error $u$ diverges from zero.

\footnotetext{
${ }^{7}$ For a more detailed discussion one can consult Janjgava and Slobodyan (2011).
} 
The E-stability of the SCE implies that there is a neighborhood of SCE where $\dot{u} / u<0$ that defines an attraction region of the SCE, see Figure 3. Whenever the mean forecast error diverges from zero, due to shocks present in the economy, but beliefs still remain in the attraction region of SCE, $u$ starts to converge to zero due to $\dot{u} / u<0$ and beliefs are attracted back to the SCE. However, when beliefs happen to be outside of the attraction region of SCE due to the updating process, they diverge from the SCE since $\dot{u} / u>0$ and the mean forecast error $u$ diverges from zero. Thus, beliefs escape the SCE whenever they appear in the region where $\dot{u} / u>0$.

The propagated dynamics due to belief updating are intuitive enough. The mean forecast error $u$ is defined as the difference between the average price $y=\mathrm{E}\left[y_{n}\right]$ and the expected price $\hat{y}_{i n}=x_{i n}^{\top} \hat{\theta}_{i n}, u=y-\hat{y}$. When firm $i$ observes higher average price than he expected, $y-\hat{y}>0$, he interprets it as a lower demand and reduces output. So, as far as $y-\hat{y}>0$ firms keep reducing their output and eventually it is closer and closer to the collusive equilibrium (CE) level.

On the other hand, when $y-\hat{y}<0$, firm $i$ interprets it as a higher demand and increases output. So, as far as $y-\hat{y}<0$ firms keep increasing their output and eventually it is closer and closer to the Nash equilibrium (NE) output.

\section{Mutual Interdependence and Collusion Frontier}

The central question with which the theory of oligopoly is concerned is how firms coordinate with each other when moving towards the collusive outcomes. Cournot thought that cartel agreements may only be maintained by "means of a formal engagement" (Vives, 2000). This view was challenged by Chamberlin (1929). He thought that in markets with a small number of firms the mechanism that elevates prices above competitive levels is the firms' mutual interdependence; the firms' recognition of their interdependence and the futility of cutting prices progressively drives the market price towards the monopoly price. 
The model developed by Janjgava and Slobodyan (2011) to study endogenous collusion possibilities captures Chamberlin's reasoning. Janjgava and Slobodyan (2011) find that the belief system (7) exhibits escapes from the SCE towards the CE when the degree of firms' mutual interdependence becomes high enough to trigger cooperation. This happens when the interdependence of firms' actions $\rho$ reaches some threshold value $\rho^{*}$, an interdependence threshold.

Following Janjgava and Slobodyan (2011), we can define the interdependence threshold $\rho^{*}$ as a solution of $\dot{u} / u=0$. Janjgava and Slobodyan (2011) concentrate on investigating a specific market where the existence of $\rho^{*}$ is assumed, and do not investigate the properties of $\dot{u} / u=0$. In this section, I investigate the properties of $\dot{u} / u=0$ and study the existence of the interdependence threshold $\rho^{*}$. It is shown that the existence of the interdependence threshold $\rho^{*}$ depends on the market size, the volatility of the firm-specific shock and the number of firms present in the market.

The mean dynamics of the forecast error along the dominant eigenvector $\bar{v}$ direction is given by

$$
\frac{\dot{u}}{u}=\left[\frac{\left(\psi /(N+1)^{2}+6\right)}{4((N-1)-\rho)(1+\rho)^{3}}\right] f(\rho),
$$

where $f(\rho)=\rho^{4}+a_{1} \rho^{3}+a_{2} \rho^{2}+a_{3} \rho+a_{4}$ represents the 4 -th order market characteristic polynomial $^{8}$ and

$$
\psi=\left(\frac{a-c}{b \sqrt{\sigma_{2}^{2}}}\right)^{2}
$$

is a market characteristic number and $\sqrt{\psi}$ denotes the normalized competitive market size. ${ }^{9}$ In the rest of the paper I refer to $\psi$ as a normalized market size.

Escapes from the SCE happens when the belief vector $\theta$ hits the $\dot{u} / u=0$ boundary and $\dot{u} / u$ changes the sign from negative to positive. The $\dot{u} / u=0$ boundary is determined by the roots of the market characteristic polynomial $f(\rho)$. $f(\rho)$ has at least one real root

\footnotetext{
${ }^{8}$ One can verify that $\rho=-1$ is not a root of the polynomial $f(\rho), f(-1)=-\frac{b^{4}(a-c)^{2} N^{2}}{(a-c)^{2}+6 b^{2}(1+N)^{2} \sigma_{2}^{2}}=$ $-b^{4} N^{2} \frac{\psi}{\left(\psi /(N+1)^{2}+6\right)}$.

${ }^{9}$ Here, $\frac{a-c}{b}$ is a perfect competition market size where a price equals a marginal cost, $\mathrm{y}=\mathrm{c}$.
} 


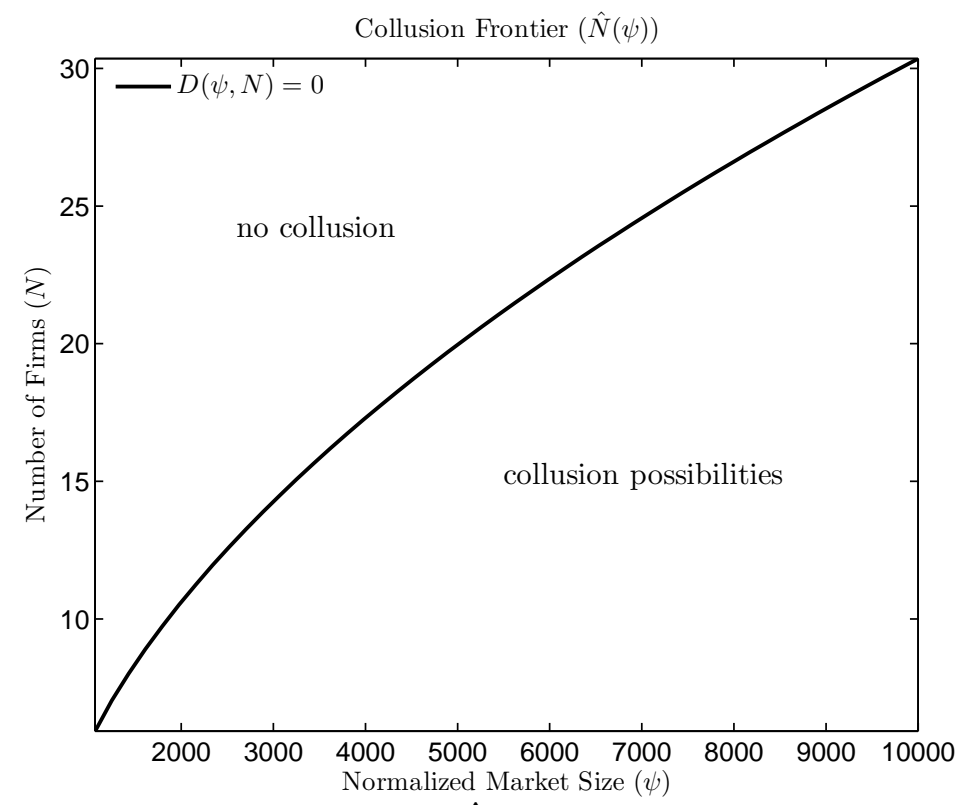

Figure 4. Collusion frontier $\hat{N}(\psi)$, a solution of $D(N, \psi)=0$.

out of its four roots and when all its roots are real only one of them are negative (see Appendix B). The interdependence threshold $\rho^{*}$ is given by the intersection of $\dot{u} / u=0$ boundary and the dominant escape path (16). So, it is one of the roots of the market characteristic polynomial $f(\rho)$.

Proposition 1. An implicit coordination on collusive outcomes is only possible when there is an interdependence threshold, $\rho^{*}$ an unstable fixed point of $\dot{u} / u$, such that $0<\rho^{*} \ll 1$. This holds when all four fixed points of $\dot{u} / u$ are real.

Proof. See Appendix B.

Let's suppose that all four fixed points $\rho_{1}<\rho_{2}<\rho_{3}<\rho_{4}$ of $\dot{u} / u$ are real where $\rho_{1}<0$ and other fixed points are positive. At the SCE both the degree of mutual interdependence $\rho$ and the mean forecast error $u$ are zero. As the SCE is E-stable $\dot{u} / u$ is negative when the degree of mutual interdependence, $\rho$, is between $\rho_{1}$ and $\rho_{2}$ and the mean forecast error $u$ converges to zero, leading beliefs to converge to the SCE. Whereas $\dot{u} / u$ is positive when $\rho \in\left(\rho_{2}, \rho_{3}\right)$, and the mean forecast error $u$ diverges from zero, leading beliefs to diverge from the SCE towards the CE. Therefore, $\rho_{2}$ is an interdependence threshold $\rho^{*}$ 
In each period, firms update their beliefs, $\theta$, about unknown demand parameters using the same price signals which lead their beliefs to become interdependent. When the level of mutual interdependence $\rho$ reaches the threshold $\rho^{*}$ firms start to coordinate on collusive outcomes, see Figure 3 , where $\theta^{*}$ is a belief vector corresponding to the degree of mutual interdependence at $\rho=\rho^{*}$.

When the number of firms, $N$, is large, price signals become non-informative due to a large content of firm-specific shocks in the aggregate output promoting belief updating and consequently a possibility of coordination on a collusive outcome to cease. This suggests that there should be some threshold number of firms, $\hat{N}$, such that if $N>\hat{N}$ that no coordination on a collusive outcome is possible.

Following the proof of Proposition 1 in Appendix B the interdependence threshold $\rho^{*}$ exist when the discriminant function of market characteristic polynomial $f(\rho)$ is negative, $D(\hat{N}(\psi), \psi)<0$. So, solving $D(\hat{N}(\psi), \psi)=0$ for $\hat{N}(\psi)$ gives us a boundary that defines a collusion frontier, a maximum number of firms which can support implicit coordination towards the collusion given $\psi$, see Figure 4 .

COROLLARY 1. In a market with a given normalized market size $(\psi)$, there is a maximum number of firms, $(\hat{N}(\psi))$, which can support implicit coordination on collusive outcomes which defines the collusion frontier. In the markets with a market structure such that $(\psi, N)$ is on or above the collusion frontier $(D(\hat{N}(\psi), \psi) \geq 0)$ no collusion possibilities may arise. Otherwise there are possibilities of coordination on collusive outcomes with a non-zero probability.

With the definition of a collusion frontier, we are now in a position to analyze dependence of the interdependence threshold $\rho^{*}(\psi, N)$ on a market structure $(\psi, N)$, see Figure 5. As was expected, the interdependence threshold $\rho^{*}(\psi, N)$ is decreasing with respect to the normalized market size $\psi$ and increasing with respect to the number of firms $N$. For example, in the market with $(\psi, N)=(9000,21)$ the correlation of the firms' actions $\rho^{*}(\psi, N)$ should be at least about 0.5 , firms to become coordinated on collusive outcomes whereas in the market with $(\psi, N)=(9000,11)$ it only needs to be 0.05 to trigger coordination on a collusive behavior. 


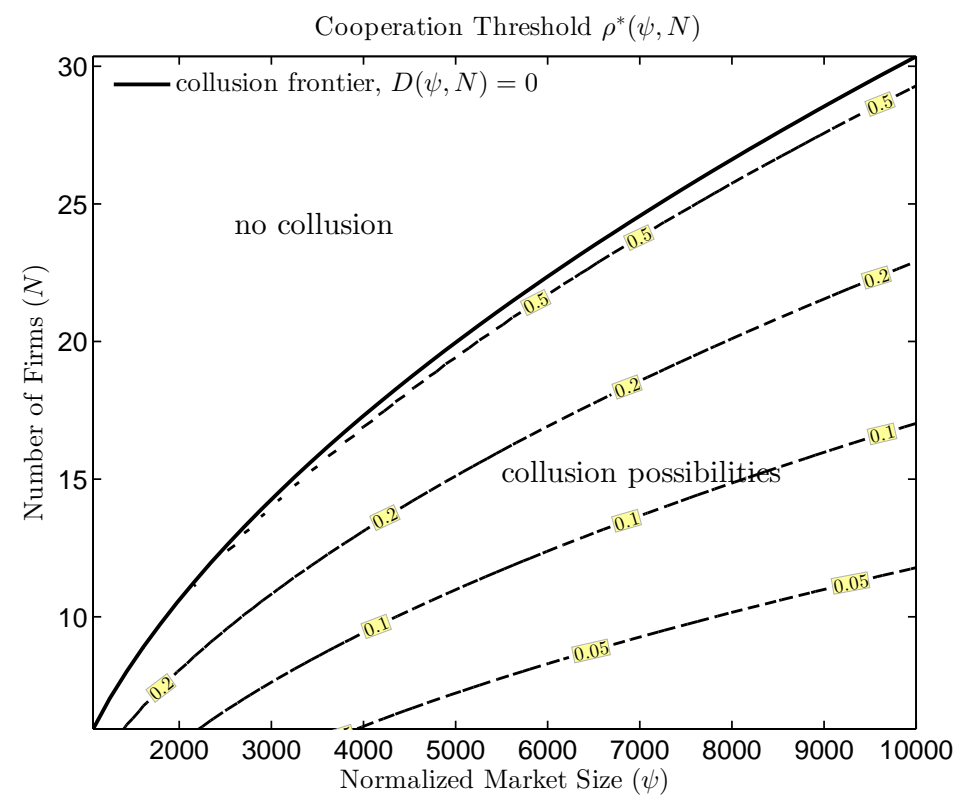

Figure 5. interdependence threshold isolines (dashed lines).

Proposition 2. In markets with a higher normalized market size $(\psi)$ and lower number of firms $(N)$ the coordination towards the collusive outcomes is triggered by a lower degree of correlation among firms'actions $\rho^{*}(\psi, N)$. Therefore, in these markets it is easier for firms to coordinate and thus, the higher the probability of attaining collusive outcomes.

The above result is quite intuitive. The higher the normalized market size, the greater the motivation to coordinate towards cooperation due to higher gains from collusion and thus, the lower the degree of mutual interdependence which is needed to attain collusive behavior. However, with a larger number of firms it is difficult to coordinate and the cooperation becomes harder. As a result we can use the interdependence threshold $\rho^{*}(\psi, N)$ to rank industries according to their propensity to collude given the market structure $(\psi, N)$. For example, in industries with more efficient technologies, the normalized market size is higher and thus it is easier to coordinate towards the collusive outcomes.

\section{Free Entry and Social Welfare}

This section deals with the social welfare analysis of free entry. The excess entry theorem shows that in homogeneous markets under free entry equilibrium we have excessive 
entry. This suggests that policy makers have to restrict entry in these markets and protect incumbents from any potential entry. These results are based on the assumption that firms cannot coordinate on collusive outcomes. However, as we saw in the previous section, in homogeneous markets under demand uncertainty firms might implicitly coordinate on collusive outcomes. A priori, the presence of collusion among firms is not desirable for social efficiency since it decreases the social welfare. The restriction of entry, a suggestion of previous research findings, makes for firms easier to coordinate towards collusion as well as to maintain it, see Proposition 2. Therefore, it is interesting to investigate whether the free entry equilibrium number of firms is still excessive when the possibility of such coordination is considered.

- Free entry equilibrium. Under free entry $N^{e}$ number of firms are established, determined by zero profit condition which yields the following expression

$$
N^{e}=\sqrt{\frac{\psi}{(1+\kappa)}}-1,
$$

where $\kappa=K /\left(b \sigma_{2}^{2}\right)$ is a normalized fixed cost.

- Social planner's problem. ${ }^{10}$ The social planner's problem is to choose the socially optimal number of firms $N^{*}$ that maximize a discounted social welfare

$$
\begin{array}{ll}
\underset{N}{\operatorname{maximize}} & \int_{0}^{\infty} W(\theta, N) e^{-r t} d t \\
\text { subject to } & \dot{\theta}=P \bar{g}(\theta, N), \\
& \dot{P}=\sigma^{-2} \bar{V}-P M(\theta) P, \\
& N \leq N^{e}, \\
& \theta(0)=\bar{\theta}, P(0)=\bar{P},
\end{array}
$$

where $W(\theta, N)$ is a social welfare function and $r=-\ln \delta$ is a common discount rate. The last constraint serves as firms' participation constraint and ensures that firms' expected

\footnotetext{
${ }^{10}$ Following the previous literature, only the second best social planner's problem is considered.
} 
profits are non-negative. When the constraint is binding free entry provides an insufficient number of firms. However, without subsidy provisions firms with negative profits are not sustainable and a feasible socially optimal number of firms coincides with the free entry number of firms. Hence, it excludes insufficient entry possibilities.

The social welfare function $W(\theta, N)$ is defined as the sum of consumer and producer surpluses and is given by the following expression

$$
W(\theta, N)=\mathrm{E}\left[\int_{0}^{\sum_{i=1}^{N} q_{n}^{i}} y(Q) d Q-\left(c \sum_{i=1}^{N} q_{n}^{i}(\theta)+K N\right) \mid y^{n-1}\right] .
$$

The entry might have two opposing effects on social welfare. One is the "business stealing" effect of entry, after Mankiw and Whinston (1986), where incumbent firms are forced to reduce output due to new entry and entry is more desirable to new entrants than it is to society. The other one is the "competition" effect that entry increases competition and hinders coordination towards the collusive outcomes. When regulatory authorities solve for the socially optimal number of firms the market structure becomes exogenous. The exogenous market structure stimulates an accommodating pricing behavior and in addition to the "business stealing" effect of entry it makes the "competition" effect of entry operative. However, the "competition" effect of entry is not present in the excess entry theorem. The "business stealing" effect reduces the social welfare whereas the "competition" effect enhances it. Thus, in opposition to the excess entry theorem the net effect of entry on social welfare depends which of these two effects outweighs each other.

Differentiating the expression for the social welfare function (20) with respect to the number of firms and evaluating it at the SCE with the free entry number of firms yields

$$
\frac{d W}{d N}=\underbrace{(y-c) \frac{\partial q}{\partial N}}_{\text {"business stealing" effect (-) }}+\underbrace{(y-c) \frac{\partial q}{\partial \rho} \frac{\partial \rho}{\partial N}}_{\text {"competition" effect (+) }} .
$$

The first term is the same "business stealing" effect described by equation (2) in Mankiw 
and Whinston (1986) whereas the second term is the "competition" effect not present in Mankiw and Whinston (1986). The latter term comes from the fact that the mutual interdependence of firms $\rho$ affects the firms actions and also new entry affects the mutual interdependence of firms $\rho$.

Let's consider two possible situations $N^{*} \geq \hat{N}(\psi)$ and $N^{*}<\hat{N}(\psi)$. When $N^{*} \geq \hat{N}(\psi)$ no coordination towards collusive behavior happens and beliefs stay in the NE. So, the social planner's dynamic problem (19) indeed becomes static problem and corresponds to the situation considered in Mankiw and Whinston (1986). Thus, whenever $N^{*} \geq \hat{N}(\psi)$ the socially optimal number of firms $N^{*}$ is a solution of the same optimization problem as in Mankiw and Whinston (1986) which is given by

$$
N^{m}=\sqrt[3]{\frac{\psi}{\kappa+1 / 2}}-1
$$

When $N^{*}<\hat{N}(\psi)$ there is a space for coordination among firms towards the collusive outcomes and the social planner's problem is no longer a static but a dynamic problem (19). The investigation of the problem is further complicated by the relatively large number of parameters $\left(a, b, c, \sigma_{2}, N\right)$ that the belief updating system (13) depends on. With no loss of generality, to simplify comparative static analysis the following transformation of beliefs are employed:

$$
\hat{\theta}=\frac{\theta+[-c, b]^{\prime}}{b \sqrt{\sigma_{2}^{2}}} .
$$

This delivers the following belief updating system

$$
\begin{aligned}
& \dot{\hat{\theta}}=P \hat{\bar{g}}(\hat{\theta}, N), \\
& \dot{P}=\sigma^{2} \bar{V}-P M(\hat{\theta}) P,
\end{aligned}
$$


where

$$
\begin{gathered}
\hat{\bar{g}}(\hat{\theta}, N)=\left[\begin{array}{l}
\hat{u} \\
\sqrt{\sigma_{2}^{2}} \hat{u} \hat{q}-\sigma_{2}^{2} \hat{\theta}_{1}
\end{array}\right], \\
\hat{u}=\frac{u}{b \sqrt{\sigma_{2}^{2}}}=\sqrt{\psi}-(N-1) \hat{q}-\hat{\theta}_{0}-\sqrt{\sigma_{2}^{2}} \hat{\theta}_{1} \hat{q}, \\
\hat{q}=\frac{q}{b \sqrt{\sigma_{2}^{2}}}=\frac{\hat{\theta}_{0}}{2\left(\hat{\theta}_{1}-1 / \sqrt{\sigma_{2}^{2}}\right)} .
\end{gathered}
$$

As a results, the dynamics of the transformed beliefs $\hat{\theta}$ depend only on the normalized market size $\psi$, the standard deviation of firm-specific shock $\sigma_{2}$, and the number of firms N.

The transformation of beliefs (22) simplifies the characterization of the parameter dependance of non-cooperative, cooperative and price war phases which are observed during the life cycle of the firms. Firms start in the SCE/NE. After some time $\tau^{N E}(N \mid \psi, \epsilon)$ when a firm's belief hits the belief threshold $\hat{\theta}^{*}$ firms start to learn to coordinate on the cooperative behavior and escape from the NE that drives the system towards the CE. The firms maintain the CE beliefs and sustain the collusion for a time period $\tau^{C E}\left(N \mid \psi, \sigma_{2}\right)$ until the unanticipated fall of mean actual price below the mean forecasted price triggers $(u<0)$ the price war that pushes the system back towards the NE and after some time $\tau^{p w}\left(N \mid \psi, \sigma_{2}\right)$ firms are back again in the NE and the cycle start again. Let's denote $T\left(N \mid \psi, \sigma_{2}, \epsilon\right)$ as the time needed for the belief system to escape from the NE towards the CE and return back to it again, thus $T\left(N \mid \psi, \sigma_{2}, \epsilon\right)=\tau^{N E}(N \mid \psi, \epsilon)+\tau^{C E}\left(N \mid \psi, \sigma_{2}\right)+$ $\tau^{p w}\left(N \mid \psi, \sigma_{2}\right)$. Utilizing this recurrent feature of the belief dynamics after every time period $T\left(N \mid \psi, \sigma_{2}\right)$, we can rewrite the social planner's objective function in (19) as follows

$$
V\left(N \mid \psi, \kappa, \delta, \sigma_{2}, \epsilon\right)=\frac{1}{1-e^{-r T\left(N \mid \psi, \sigma_{2}, \epsilon\right)}} \int_{0}^{T\left(N \mid \psi, \sigma_{2}, \epsilon\right)} \Omega\left(\hat{\theta}, N \mid \psi, \kappa, \sigma_{2}, \epsilon\right) e^{-r t} d t
$$

where $\Omega\left(\hat{\theta}, N \mid \psi, \kappa, \sigma_{2}, \epsilon\right)=\frac{W(\hat{\theta}, N)}{b \sigma_{2}^{2}}$ is the normalized social welfare function. 


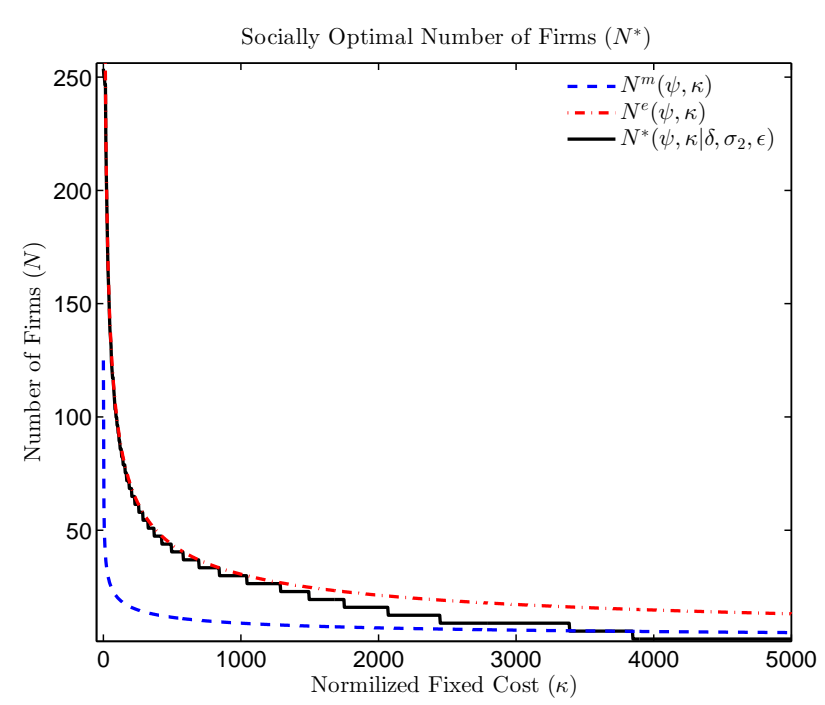

(a)

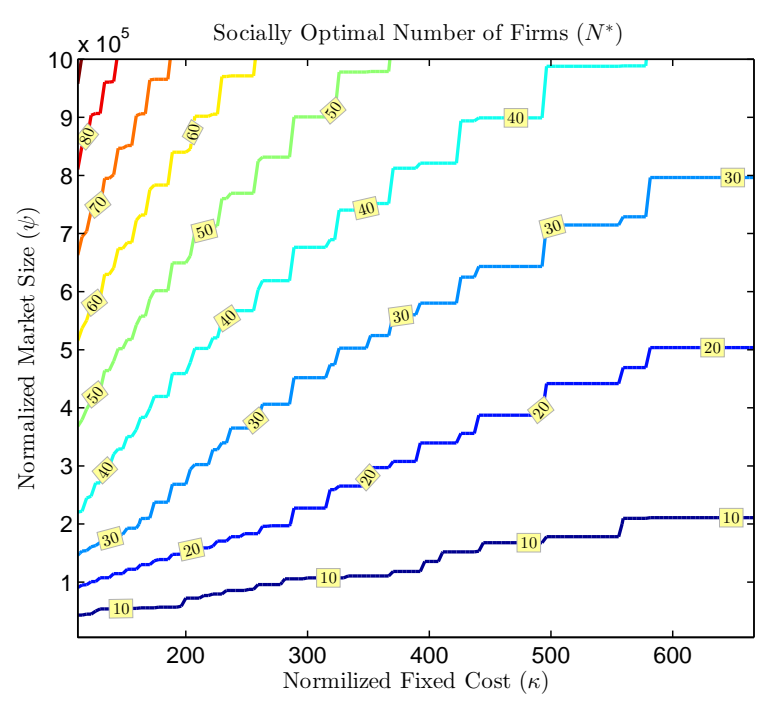

(b)

FIgURE 6. The solution of the social planner's problem and its comparative statics, $(\delta=$ $\left.0.98, \sigma_{2}=0.1, \epsilon=1 / 365\right)$ : (a) depicts the socially optimal number of firms $N^{*}\left(\psi, \kappa \mid \delta, \sigma_{2}, \epsilon\right)$ (solid line) and compares it with the socially optimal number of firms $N^{m}(\psi, \kappa)$ (dashed blue line) when possibility of coordination towards collusion is ignored as well as with the free entry equilibrium number of firms $N^{e}(\psi, \kappa)$ (dash-dot red line). The normalize market size $\psi$ is set at $10^{6}$ and $\hat{N}(\psi)=348$; (b) depicts the isolines of the socially optimal number of firms $N^{*}\left(\psi, \kappa \mid \delta, \sigma_{2}, \epsilon\right)$ and shows its comparative statics properties.

A natural upper bound for the solution is given by the following expression

$$
N^{*} \leq \min \left\{\hat{N}(\psi), N^{e}(\psi, \kappa)\right\}
$$

There is no analytical solution to the problem (19) and we have to rely on numerical analysis.

- Numerical results and comparative statics. Numerical results are obtained with the parameter values of $\left(\delta, \sigma_{2}, \epsilon\right)$ set at $(0.98,0.10,1 / 365)$. The numerical solution of the social planner's problem and its properties are depicted in Figure 6. Figure 6a compares the socially optimal number of firms $N^{*}\left(\psi, \kappa \mid \delta, \sigma_{2}, \epsilon\right)$ under demand uncertainty both with the free entry equilibrium number of firms $N^{e}(\psi, \kappa)$ and the socially optimal number of firms $N^{m}(\psi, \kappa)$ under the perfect information of Mankiw and Whinston (1986). We can see that for lower values of the normalized fixed cost $\kappa$ the participation constraint (zero profit condition) is binding and in contrast to previous studies, such as Mankiw 
and Whinston (1986) and subsequent research, the free entry equilibrium delivers an insufficient rather than excessive entry when the "competition effect" of entry is modeled explicitly.

The comparative statics of the optimal solution $N^{*}\left(\psi, \kappa \mid \delta, \sigma_{2}, \epsilon\right)$ can be examined simply by plotting its isolines, see Figure 6b. From the isolines of the solution we can see that $N^{*}\left(\psi, \kappa \mid \delta, \sigma_{2}, \epsilon\right)$ is an increasing function with respect to the normalized market size $\psi$ whereas with respect to the normalized fixed cost $\kappa$ it is decreasing, as can also be seen in Figure 6a.

The results are quite intuitive. The higher the normalized market size $\psi$ the higher the possibility of coordination towards the collusive outcome (see Proposition 2) and controlling for the "competition" effect becomes even more important when assessing the socially optimal number of firms. Thus, the higher the normalized market size $\psi$ the higher the gain in social welfare from additional entry in hindering possibilities of coordination on a collusive outcome. On the other hand, higher the normalized market size $\psi$ less business should be "stolen" with each additional entry. Hence, the socially optimal number of firms is increasing with respect to the normalized market size $\psi$.

The entry effect on social welfare with regards to the normalized fixed costs are slightly different as it affects only the "business stealing" effect of entry but not the possibility of coordination towards collusion. When the normalized fixed cost is high more business needs to be "stolen" from existing firms for a new firm to operate profitably. Thus, with a high normalized fixed cost, the net marginal effect of entry on social welfare is negative and the free entry number of firms exceeds the socially optimal number of firms.

The results can be summarized in the following proposition:

PrOpOSITION 3. In markets with a low normalized fixed cost $(\kappa)$ and a high enough normalized market size $(\psi)$, the zero profit condition might be binding and the number of firms under free entry equilibrium might be socially insufficient rather than excessive.

The results show that the findings of Mankiw and Whinston (1986) are a special case and whether the free entry equilibrium number of firms is excessive or not depends on 
the market structure and conditions when demand parameter uncertainty is considered. Hence, the traditional wisdom in industrial organization that free entry is desirable for social efficiency is valid in these markets.

\section{Conclusion}

In this paper I have studied the social efficiency of free entry under demand parameter uncertainty. Previous research on free entry and its welfare implications in homogeneous product markets under perfect information shows that the free entry equilibrium delivers excessive entry, known as the excess entry theorem and suggests restrictive entry regulation policies. I have shown that the introduction of demand parameter uncertainty alters the results of the excess entry theorem and the restrictive entry regulation policies might facilitate collusion possibilities.

When entry is restricted by the regulatory authorities the market structure becomes exogenous. The theory of endogenous market structure has shown that when entry is exogenous it stimulates firms to coordinate their actions towards accommodating pricing behavior to increase prices (Etro (2010)). However, the excess entry theorem does not consider this fact and its predictions are solely based on the "business stealing" effect of entry where incumbent firms are forced to reduce output due to new entry and entry is more desirable to new entrants than it is to society. Under restricted entry a fixed number of firms operate in the market and the abuse of market power and the possibility of accommodating pricing behavior makes the additional effect of entry, the "competition" effect operative. The "competition" effect reduces market power and hinders the possibility of coordination on a collusive outcome. These two effects of entry impact differently on social welfare and whether entry is socially efficient depends not only on the "business stealing" effect but also on the "competition" effect.

In this paper, I show that learning the unknown demand parameters when market structure is exogenous leads firms to implicitly coordinate on collusive outcomes and 
allows the study of the "competition" effect of entry along with the "business stealing" effect. I find that the competition effects of entry outweigh the "business stealing" effects of entry in the markets with a high enough competitive market size and supports the validity of the traditional wisdom in industrial organization that the free entry is desirable for social efficiency in homogeneous product markets.

Additionally, I derive the collusion frontier which shows the maximum number of firms which might support implicit coordination on collusive outcomes due to demand uncertainty in the homogeneous market given the market size. It can be used to assess the bias of a specific market towards possibilities of implicit coordination on collusive outcomes. 


\section{Appendix}

\section{A. E-stability of the SCE}

To find the steady-state of the system of ODEs (12) we have to solve $\dot{\theta}^{i}=0$ for all $i \in\{1, \ldots, N\}$. Since $P^{i}$ is positive definite matrix, a solution for the steady-state can be obtained through solving $\bar{g}\left(\theta^{i}, \ldots, \theta^{N}\right)=0$ for all $i \in\{1, \ldots, N\}$.

Let, $q^{i}=\mathrm{E}\left[q_{n}^{i}\right], y=\mathrm{E}\left[y_{n}\right]=a-b \sum_{i=1}^{N} q^{i}$, and $u^{i}=\mathrm{E}\left[u_{n}^{i}\right]=y-\theta_{0}^{i}-\theta_{1}^{i} q^{i}$, then by definition $\bar{g}\left(\theta^{i}, \ldots, \theta^{N}, N\right)$ is given by the following expression

$$
\bar{g}\left(\theta^{i}, \ldots, \theta^{N}\right)=\left[\begin{array}{l}
u^{i} \\
u^{i} q^{i}-\left(b+\theta_{1}^{i}\right) \sigma_{2 i}^{2}
\end{array}\right] .
$$

Solving $\bar{g}\left(\theta^{i}, \ldots, \theta^{N}, N\right)=0$ gives

$$
\begin{gathered}
u^{i}=0, \\
\theta_{1}^{i}=-b .
\end{gathered}
$$

Using (26) and (5) in (25) we get

$$
\theta_{0}^{i}=2 y-c
$$

Therefore, as was expected the steady-state value of the belief vector $\theta^{i}$ are the same among the firms and is given by

$$
\theta^{i}=\left[\frac{2 a+(N-1) c}{N+1},-b\right]^{\prime}
$$

which is indeed the SCE belief $\bar{\theta}$.

Following Evans and Honkapohja (2001), the sufficient condition for E-stability of the system of ODEs (12) is that the Jacobian of its belief updating part at the SCE has all 
eigenvalues with a negative real part. The Jacobian is given by the following matrix

$$
\underset{N \times N}{\bar{h}_{\theta}}=\left[\begin{array}{cccc}
\frac{\bar{P}_{1} \partial \bar{g}_{1}(\bar{\theta})}{\partial \theta_{1}} & \frac{\bar{P}_{1} \partial \bar{g}_{1}(\bar{\theta})}{\partial \theta_{2}} & \ldots & \frac{\bar{P}_{1} \partial \bar{g}_{1}(\bar{\theta})}{\partial \theta_{N}} \\
\frac{\bar{P}_{2} \partial \bar{g}_{2}(\bar{\theta})}{\partial \theta_{1}} & \frac{\bar{P}_{2} \partial \bar{g}_{2}(\bar{\theta})}{\partial \theta_{2}} & \ldots & \frac{\bar{P}_{2} \partial \bar{g}_{2}(\bar{\theta})}{\partial \theta_{N}} \\
\vdots & \ldots & \ddots & \vdots \\
\frac{\bar{P}_{N} \partial \bar{g}_{N}(\bar{\theta})}{\partial \theta_{1}} & \frac{\bar{P}_{N} \partial \bar{g}_{N}(\bar{\theta})}{\partial \theta_{2}} & \ldots & \frac{\bar{P}_{N} \partial \bar{g}_{N}(\bar{\theta})}{\partial \theta_{N}}
\end{array}\right],
$$

where

$$
\frac{\bar{P}_{i} \partial \bar{g}_{i}(\bar{\theta})}{\partial \theta_{i}}=\left[\begin{array}{cc}
-1 & 0 \\
0 & -1
\end{array}\right], \frac{\bar{P}_{i} \partial \bar{g}_{i}(\bar{\theta})}{\partial \theta_{j}}=\left[\begin{array}{cc}
-1 / 2 & \bar{q} \\
0 & 0
\end{array}\right]=B .
$$

We can rewrite the Jacobian $\bar{h}_{\theta}$ in a compact way

$$
\bar{h}_{\theta}=(J-I) \otimes B-I,
$$

where $J$ is a $N \times N$ matrix of ones and $I$ is a identity matrix with ones on the main diagonal and zeros elsewhere.

It is well known or we can easily verify that $J$ has $N-1$ multiple eigenvalues of 0 and one eigenvalue of $N$. Let the spectrum of a matrix $J-I$, and $B$ matrices be $\lambda$ and $\mu$ respectively, then we have

$$
\lambda=(-1, \ldots,-1, N-1), \mu=(-1 / 2,0) .
$$

The eigenvalues of the Kronecker product of $J-I$, and $B$ matrices $(J-I) \otimes B$ are

$$
\begin{gathered}
\lambda^{i} \mu^{i}, i=1, \ldots, N, j=1, \ldots, N . \\
(1 / 2, \ldots, 1 / 2,-(N-1) / 2,0, \ldots, 0) .
\end{gathered}
$$

Finally, the eigenvalues of $\bar{h}_{\theta}$ are given by

$$
\lambda^{i} \mu^{i}-1, i=1, \ldots, N, j=1, \ldots, N
$$




$$
(-1 / 2, \ldots,-1 / 2,-(N-1) / 2-1,-1, \ldots,-1)
$$

We see that all eigenvalues of the Jacobian $\bar{h}_{\theta}$ are negative, which proves the E-stability of the system of ODEs (12).

\section{B. Analyzing the Market Characteristic Polynomial}

This appendix provides proof for Proposition 1. First, let's prove the following two propositions before dealing directly with Proposition 1.

PROPOSITION 4. The market characteristic polynomial $f(\rho)$ has at least one real root. Therefore, it has either all four roots real or two real and two complex conjugate roots since $f(\rho)$ is a 4-th order polynomial.

Proof. Since $f(0)<0, f(-\infty)>0$ and $f(+\infty)>0$ the market characteristic polynomial can not have all roots complex. Moreover, $f(\rho)$ is 4-th degree polynomial and therefore, it can have either four real roots (one negative and three positive or three negative and one positive) or two real (one positive and one negative) and two complex conjugate roots.

The market characteristic polynomial $f(\rho)$ is associated with the following discriminant function.

$$
D(\psi, N)=A_{1}(N) \psi^{5}+A_{2}(N) \psi^{4}+A_{3}(N) \psi^{3}+A_{4}(N) \psi^{2}+A_{5}(N) \psi+A_{6}(N)
$$

Whether $f(\rho)$ has all roots real or two real and two complex conjugate roots depends on the sing of its discriminant: ${ }^{11}$

$$
\begin{array}{ll}
D(\psi, N)>0 & \text { two real and two complex conjugate roots, } \\
D(\psi, N)=0 & \text { two simple real and one twofold real roots, } \\
D(\psi, N)<0 & \text { four real roots. }
\end{array}
$$

\footnotetext{
${ }^{11}$ One can check that it is not possible to have one simple real and one threefold real roots since $\psi$ is positive.
} 
Solving $D(\psi, N)=0$ for $N$ we obtain a threshold boundary $\hat{N}(\psi)$, the number of firms supporting two simple real and one twofold real roots, dividing the parameter space into two subspaces, $D(\psi, N) \geq 0$ and $D(\psi, N)<0$, Figure 7 . For $N \geq 2, D(\psi, N)<0$ is possible when $\psi>\underline{\psi}=1064$. So, the lower bound for $\psi$ s.t $D(\psi, N)<0$ for $N \geq 2$ is $\underline{\psi}=1064$.

PROPOSITION 5. The market characteristic polynomial $f(\rho)$ has only one negative root when all its roots are real.

Proof. According Descartes' rule of signs, to have only one negative root it is enough to show that coefficients of $f(\rho) a_{2}<0$ and $a_{3}>0$ when all roots are real, $D(\psi, N)<0$. We can check that $a_{3}>0$ implies $a_{2}<0$. For $N \geq 2, a_{3}>0$ when

$$
\psi>\frac{4(N+1)^{2}(N(N+2)-6)}{(N-1)^{2}}
$$

From Figure 7 we see that when all roots are real $(D(\psi, N)<0) a_{3}>0$. This proves that when all roots are real $f(\rho)$ can only have one negative root.

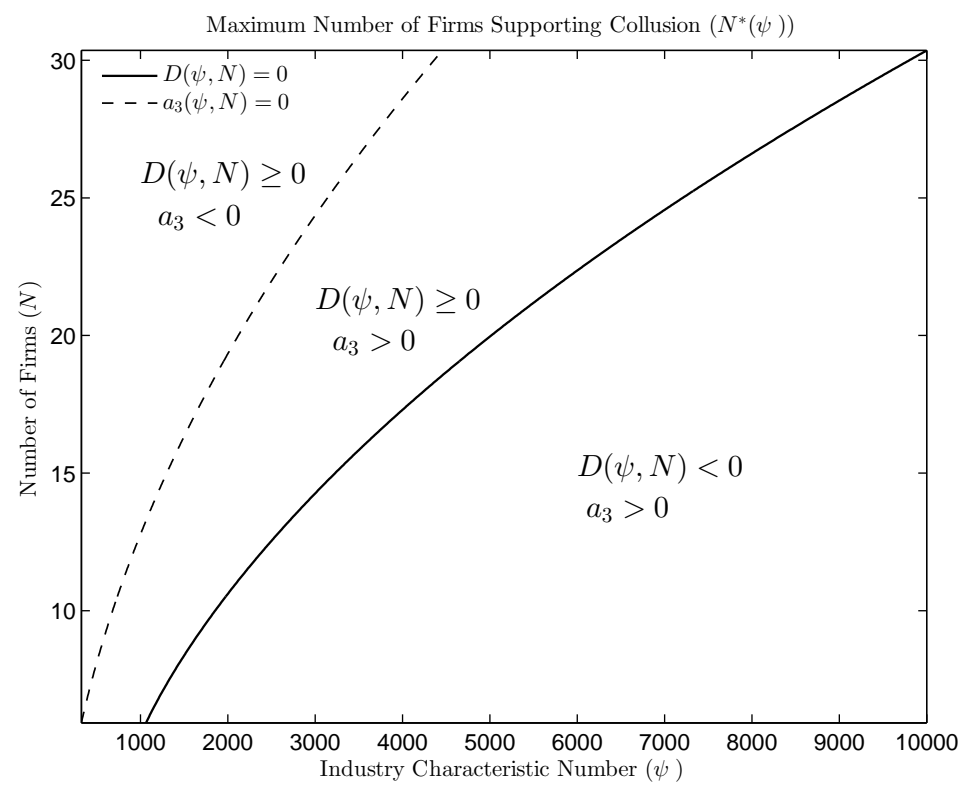

FIgURE 7. Shows the maximum number of firms supporting collusion $\hat{N}(\psi)$ given market characteristic number $\psi$ and also that $a_{3}$ is positive when all roots of $f(\rho)$ are real.

Now, we can go back to Proposition 1. From the above propositions we know that we can have only two possibilities: 1) four real roots (one negative and three positive) and 2) 


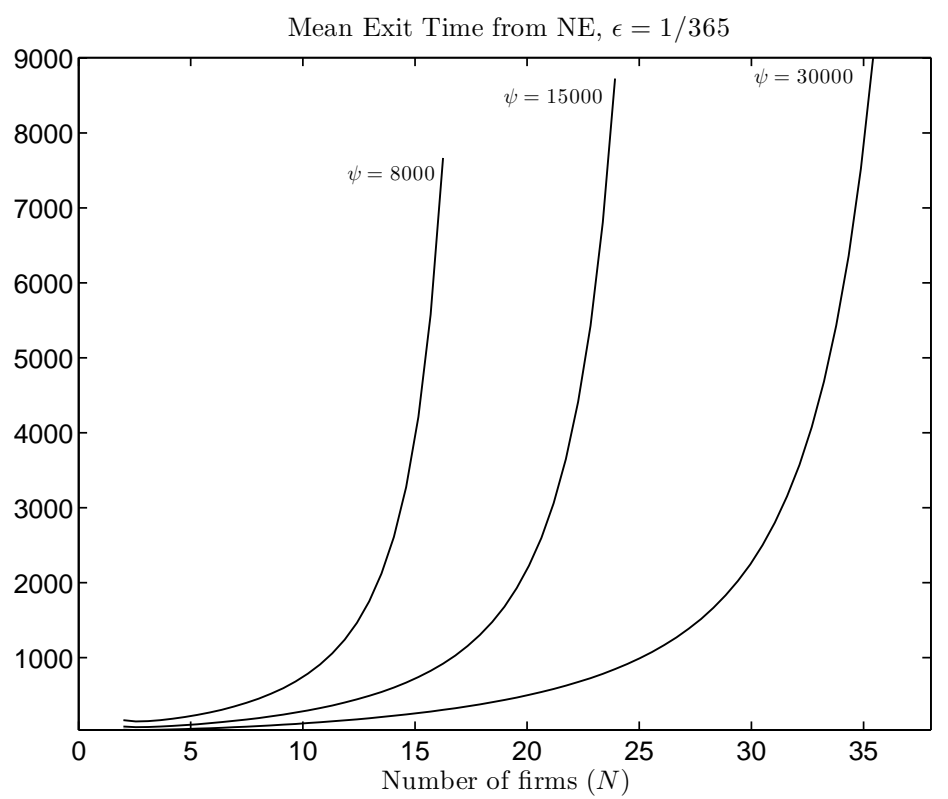

Figure 8. Mean exit time from NE when $D(\psi, N)<0$

two real (one positive and one negative) and two complex conjugate roots.

Case 1: $D(\psi, N)<0$, four real roots $\rho^{i}, i=\{1,2,3,4\}$ (in the increasing order)

Since the SCE is E-stable $f(\rho)$ is negative for $\rho \in\left(\rho_{1}, \rho_{2}\right) \cup\left(\rho_{3}, \rho_{4}\right)$ and positive otherwise. Therefore, when $\rho \in\left(\rho_{2}, \rho_{3}\right), \dot{u} / u$ becomes positive and belief system escapes from the SCE and we observe cooperative behavior. Thus, $\rho_{2}$ serves as an interdependence threshold $\rho^{*}(\psi, N)$. The cooperative behavior to be maintained, the belief updating system should drive $\rho$ to cross the threshold $\rho^{*}(\psi, N)$ in a finite time. Figure 8 depicts that for the range of parameter values, $(\psi, N)$ a mean hitting time to the threshold $\rho^{*}(\psi, N)$ is finite and therefore the mean exit time from the NE is finite as well. This effectively means that when $D(\psi, N)<0$ we might observe implicit coordination on collusive outcomes and escape from the NE towards the CE.

Case 2: $D(\psi, N) \geq 0$, two real and two complex conjugate roots

For the parameter values when $D(\psi, N)$ becomes non-negative $\rho_{2}$ and $\rho_{3}$ becomes complex numbers and we are left only with two real roots $\rho_{1}$ and $\rho_{4}$. Therefore, we may observe escapes from the NE only when $\rho>\rho_{4}$. The $\rho_{4}$ is the largest positive root of $f(\rho)$ and now the belief system needs more time to exit from the NE than in the case of 


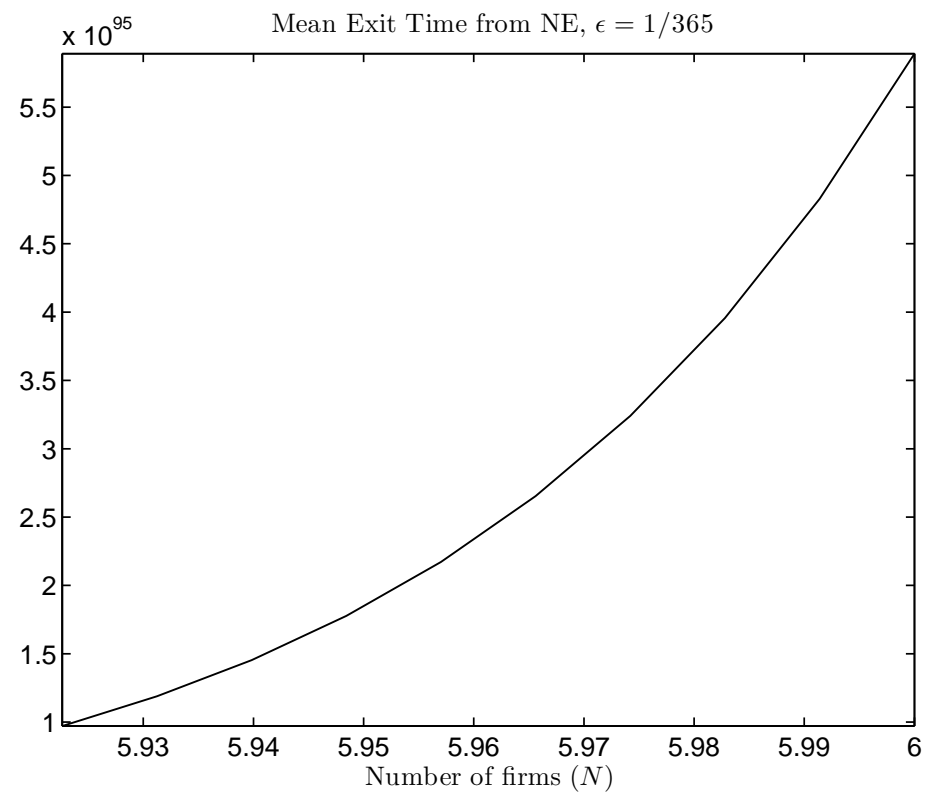

Figure 9. Mean exit time from NE when $D(\psi, N) \geq 0$.

$D(\psi, N)<0$. The bounds for the largest positive root of $f(\rho)$ are given by

$$
(N+1)\left(\sqrt{\frac{2 N}{N+1}}-1\right) \leq \rho_{4} \leq(N-1)
$$

It is a nice observation that bounds does not depend on $\psi$. Even using the lower bound we can show that the mean exit time from the $\mathrm{NE}$ when $D(\psi, N) \geq 0$ is a large number, Figure 9.

Therefore, we can conclude that when $D(\psi, N) \geq 0$ we do not observe implicit cooperation among the firms whereas otherwise we might. This effectively means that in an industry with the characteristic number $\psi$ a tacit collusion can be observed if, and only if, $D(\psi, N)<0$, or in other words the number of firms does not exceed $\hat{N}(\psi), N \in$ $[2, \ldots, \hat{N}(\psi))$. This proves Proposition 1 .

\section{Mean Hitting Time}

Consider a one-dimensional Ornstein-Uhlenbeck process

$$
d \xi=-\xi d t+\sqrt{2} d W,
$$


where $W$ is a Wiener process.

Following Ricciardi and Sato (1988), the mean hitting time $\tau=\inf \left\{t \mid \xi_{t}=\xi^{*}\right\}$ to a threshold $\xi^{*}$ for the Ornstein-Uhlenbeck process $\xi$ when it start at zero can be evaluated with the following expression

$$
\mathrm{E}[\tau]=\frac{1}{2} \sum_{k=1}^{\infty} \frac{\left(\sqrt{2} \xi^{*}\right)^{k}}{k !} \Gamma\left(\frac{k}{2}\right),
$$

where $\Gamma(\cdot)$ is the gamma function.

Following Kolyuzhnov, Bogomolova, and Slobodyan (2006), we can show that belief dynamics around the SCE are approximated by the following one-dimensional OrnsteinUhlenbeck process

$$
d \hat{\varphi}=-\hat{\varphi} d t+\sqrt{\epsilon \lambda_{\bar{\Sigma}}} d W
$$

where $\hat{\varphi}=v^{\prime}(\theta-\bar{\theta}), v=\hat{v} /\|\hat{v}\|, \hat{v}=\left(\bar{v}_{1}^{\prime}, \ldots, \bar{v}_{N}^{\prime}\right), \bar{v}^{\prime i}=\bar{v}$, and $\lambda_{\bar{\Sigma}}=2 b^{2}(N-1)\|\bar{v}\|$.

We are interested in the mean hinting time of $\hat{\varphi}$ to the threshold $\hat{\varphi}^{*}$ which can be assessed using the expression (29) with the transformed threshold $\xi^{*}=\sqrt{2 /\left(\epsilon \lambda_{\bar{\Sigma}}\right)} \hat{\varphi}^{*}$. The expression for the threshold $\xi^{*}$ is given by

$$
\xi^{*}=\frac{1}{\sqrt{\epsilon}} \sqrt{\frac{N}{N-1}} \rho^{*}(\psi, N) .
$$

\section{References}

BAI, J., ANd S. Ng (2002): “Determining the Number of Factors in Approximate Factor Models," Econometrica, 70(1), 191-221.

Balvers, R., and T. Cosimano (1990): “Actively Learning about Demand and the Dynamics of Price Adjustment," Economic Journal, 100(402), 882-98.

Balvers, R. J., and T. F. Cosimano (1993): “Periodic learning about a hidden state variable," Journal of Economic Dynamics and Control, 17(5Ü6), 805 - 827. 
Bernanke, B. S., and J. Boivin (2003): "Monetary policy in a data-rich environment," Journal of Monetary Economics, 50(3), 525-546.

Berry, S. T., and J. Waldfogel (1999): "Free Entry and Social Inefficiency in Radio Broadcasting," RAND Journal of Economics, 30(3), 397-420.

Chamberlin, E. (1929): “Duopoly: Value Where Sellers are Few,” The Quarterly Journal of Economics, 44(1), 63-100.

Cho, I., N. Williams, and T. Sargent (2002): “Escaping Nash inflation,” Review of Economic Studies, 69(1), 1-40.

Dekel, E., D. Fudenberg, and D. K. Levine (2004): “Learning to play Bayesian games,” Games and Economic Behavior, 46(2), $282-303$.

Etro, F. (2010): “Endogenous market structures and antitrust policy," International Review of Economics, 57, 9-45, 10.1007/s12232-009-0088-3.

Evans, G., and S. Honkapohja (2001): Learning and Expectations in Macroeconomics. Princeton University Press, Princeton, Princeton University Press, Princeton, NJ.

Fudenberg, D., and D. K. Levine (1993): “Self-Confirming Equilibrium,” Econometrica, 61(3), 523-545.

Fudenberg, D., And D. K. Levine (2009): “Learning and Equilibrium,” Annual Review of Economics, 1(1), 385-420.

Harvey, A. (1992): Forecasting, Structural Time Series Models and Kalman Filter. university Press, Cambridge.

Janjgava, B., and S. Slobodyan (2011): "Duopoly Competition, Escape Dynamics and Non-cooperative Collusion," CERGE-EI Working Papers wp445, The Center for Economic Research and Graduate Education - Economic Institute, Prague. 
Kolyuzhnov, D., A. Bogomolova, and S. Slobodyan (2006): “Escape Dynamics: A Continuous Time Approach," .

Ljungevist, L., And T. J. Sargent (2004): Recursive Macroeconomic Theory. The MIT Press.

Mankiw, N. G., and M. D. Whinston (1986): “Free Entry and Social Inefficiency,” RAND Journal of Economics, 17(1), 48-58.

Ohkawa, T., M. Okamura, N. Nakanishi, and K. Kiyono (2005): “The Market Selects The Wrong Firms In The Long Run," International Economic Review, 46(4), 1143-1165.

Perry, M. K. (1984): “Scale Economies, Imperfect Competition, and Public Policy,” Journal of Industrial Economics, 32(3), 313-33.

Ricciardi, L. M., and S. Sato (1988): "First-passage-time density and moments of the Ornstein-Uhlenbeck process," Journal of Applied Probability, 25, 43-57.

Sargent, T. (1999): The Conquest of American Inflation. Princenton University Press, Princeton.

Sargent, T., and S. Williams (2005): "Impacts of Priors on Convergence and Escapes from Nash Inflation," American Economic Review, 8, 360-391.

Sargent, T. J. (2008): "Evolution and Intelligent Design," American Economic Review, 98(1), 5-37.

Slade, M. E. (1989): “Price Wars in Price-Setting Supergames,” Economica, 56(223), 295310.

Stock, J. H., and M. W. Watson (2002): “Forecasting Using Principal Components from a Large Number of Predictors," Journal of the American Statistical Association, 97(460), pp. 1167-1179.

Suzumura, K. (2012): “Excess entry theorems after 25 years," Japanese Economic Review, 63(2), 152-170. 
Suzumura, K., and K. Kiyono (1987): “Entry Barriers and Economic Welfare,” Review of Economic Studies, 54(1), 157-67.

Vives, X. (2000): Oligopoly Pricing: Old Ideas and New Tools. MIT Press.

Weizsaker, C. (1980): "A Welfare Analysis of Barriers to Entry," Bell Journal of Economics, 11(2), 399-420. 


\section{Working Paper Series}

ISSN 1211-3298

Registration No. (Ministry of Culture): E 19443

Individual researchers, as well as the on-line and printed versions of the CERGE-EI Working Papers (including their dissemination) were supported from institutional support RVO 67985998 from Economics Institute of the ASCR, v. v. i.

Specific research support and/or other grants the researchers/publications benefited from are acknowledged at the beginning of the Paper.

(c) Batlome Janjgava, 2013

All rights reserved. No part of this publication may be reproduced, stored in a retrieval system or transmitted in any form or by any means, electronic, mechanical or photocopying, recording, or otherwise without the prior permission of the publisher.

Published by

Charles University in Prague, Center for Economic Research and Graduate Education (CERGE) and

Economics Institute of the ASCR, v. v. i. (EI)

CERGE-El, Politických vězňu 7, 11121 Prague 1, tel.: +420 224005 153, Czech Republic.

Printed by CERGE-EI, Prague

Subscription: CERGE-EI homepage: http://www.cerge-ei.cz

Phone: + 420224005153

Email: office@cerge-ei.cz

Web: http://www.cerge-ei.cz

Editor: Marek Kapička

The paper is available online at http://www.cerge-ei.cz/publications/working_papers/.

ISBN 978-80-7343-299-7 (Univerzita Karlova. Centrum pro ekonomický výzkum a doktorské studium)

ISBN 978-80-7344-291-0 (Akademie věd České republiky. Národohospodářský ústav) 
CERGE-EI

P.O.BOX 882

Politických vězňů 7

11121 Praha 1

Czech Republic http://www.cerge-ei.cz 